\title{
Preoccupation with Weight and Eating Patterns of Lebanese and Cypriot Female Students
}

\author{
Ioanna Katsounari ${ }^{1}$, Nadine Zeeni ${ }^{2}$ \\ ${ }^{1}$ Social Work Department, Frederick University, Nicosia, Cyprus \\ ${ }^{2}$ Department of Natural Sciences, School of Arts and Sciences, \\ Lebanese American University, Byblos, Lebanon \\ Email: jkatsounari@yahoo.com, nadine.zeeni@lau.edu.lb
}

Received January $12^{\text {th }}, 2012$; revised February $13^{\text {th }}, 2012$; accepted March $12^{\text {th }}, 2012$

\begin{abstract}
This comparative cross-cultural study explores the prevalence of preoccupation with weight and eating patterns among female university students in two distinct cultural contexts, Cyprus and Lebanon. Data was collected by means of self-administered questionnaires to 200 students from each culture. To gather the data for this study, the Dutch Eating Behavior Scale was used for the assessment of eating behaviors. Body Mass Index (BMI) and Weight directed behavior were also calculated. The Pearson ProductMoment Correlation Coefficient was used to determine whether there is a linear relationship between students' BMI and eating behaviors. Findings suggested that with respect to culture and pre-occupation with weight, Cypriot students are more pre-occupied with their weight. However, Lebanese students received higher emotional and external eating scores. In addition, a positive relationship between Body Mass Index, restrained and emotional eating was found in both cultures Also, in both cultures there was a significant positive relationship between restrained and emotional eating, emotional and external eating. These findings suggest that in the Lebanese culture, eating dysfunction among women may be due to responsiveness to external and emotional cues while in the Cypriot culture may be due to an over pre-occupation with weight fuelled by sociocultural agents. Understanding the underlying causes of eating deviations and the existing elements in each culture which promote these deviations could lead to better prevention efforts in two societies where the rise in eating disturbances has been alarming.
\end{abstract}

Keywords: Cross-Cultural Study; Weight Directed Behavior; Eating Behaviors

\section{Introduction}

Eating in response to environmental cues and emotions has been recognized as a prominent aspect of eating behaviour which is common but also as leading to problematic eating behaviors such as excessive eating, binge-eating and clinically diagnosable eating disorders such as bulimia nervosa (Lindeman \& Stark, 2001). Although the documentation of these eating behaviours as problematic has been increasing, empirical investigations of these phenomena in different cultural groups have been limited.

Three prominent eating responses which have been recognized to be implicated in pathological eating behaviors are emotional, external, and restrained eating. Different theories have described these responses to environmental cues which can be classified as individual eating patterns or behaviors.

Psychosomatic theory defines "emotional eating" as the consumption of food which occurs when an individual responds to arousal states such as anger, fear, or anxiety by excessive eating (e.g. Polivy, Herman, \& McFarlane, 1994; van Strien, Frijters, Bergers, \& Defares, 1986). It further states that obese persons engage in excessive eating in response to negative emotions, while normal weight persons have more adaptive coping mechanisms and do not eat in response to emotional distress (Faith et al., 1997). Therefore, emotional eating has been linked with various forms of overeating such as obesity and bulimic tendencies (e.g. Eldredge \& Agras, 1996; van Strien, 1996) and emotional eating research has often focused on obese popula- tions. Ogden (1993) argued that emotional eating might be a consequence of the general psychological vulnerability related to eating disorder psychopathology.

Recent research has indicated that people in different cultures respond to emotional experiences through different forms of eating behaviours and that emotional-eating patterns have connections with obesity, anorexia nervosa, and bulimia (Butler, Lee, \& Gross, 2007; Luomala, Sirieix, \& Tahir, 2009, Macht \& Simons, 2000; Geliebter \& Aversa, 2003). Despite indications that emotional eating is problematic, empirical documentation of this phenomenon is not as extensive (Nquyen-Rodriguez, Unger, \& Spruizt-Metz, 2009). It has been argued that the lack of specificity of emotion inhibits detailed study of the psychological precursors to overeating (Arnow, Kenardy, \& Agras, 1995).

Externality theory focuses on "external eating" which is eating in response to food-related stimuli regardless of the internal state of hunger or satiety (Schachter, Goldman, \& Gordon, 1968). Both theories view an individual's misperception of his/her internal state prior to eating as a contributing factor in the development of obesity (Robbins \& Fray, 1980). However, the relationship between emotional and external eating has not been confirmed through correlational studies so far (Ogden, 1993).

Finally, individuals may react to being overweight by consciously restricting their food intake regardless of whether they are emotional or external eaters (Rodin, 1978). Restrained eat- 
ing is defined as a persistent fixation on dieting and weight, and the amount of food eaten is restricted for the purpose of weight loss or maintenance. Restrained eaters commonly experience weight fluctuations due to alternations between dieting and pronounced lapses in dietary adherence (Ruderman, 1985). In addition, research indicates that when exposed to significant stressors, restrained eaters' eating becomes disinhibited, resulting in the consumption of significantly larger quantities of food than when not distressed (Heatherton, Striepe, \& Wittenberg, 1998; Oliver, Huon, Zadro, \& Williams, 2001; Tanofsky-Kraff, Wilfley, \& Spurrell, 2000). Dietary restriction has been implicated as a risk factor in the development of obesity, binge-eating, and clinically diagnosable eating disorders, such as bulimia nervosa (Stice, Presnell, \& Spangler, 2002). As such, restricted eating should be studied with the ultimate goal of preventing eating disorders.

The relationship between emotional eating patterns and Body Mass Index (BMI) has been studied before with conflicting findings.

A cross-sectional study in the Netherlands assessed overweight-level and overeating in relation to dietary restraint, emotional eating and external eating, using the Dutch Eating Behaviour Questionnaire (DEBQ). It was found that an individual's final level of body weight may possibly be determined more by people's tendency toward emotional eating than by people's sensitivity to environmental food cues. Specifically, it was found that dietary restraint and emotional eating moderated the relationship between overconsumption and overweight. Therefore, dietary restraint may prevent people who overeat from getting overweight (van Strien et al., 2009).

Pothos, Tapper, and Calitri (2009), examined the possible correlation of BMI with the DEBQ measures. Contrary to expectations from related literature, for females there was a negative correlation between BMI and external eating.

Nolan, Halperin, and Geliebter (2010) studied the responses of 232 male and female participants using the Emotional Appetite Questionnaire (EMAQ) which includes ratings of tendency to eat in response to both positive and negative emotions and situations. Emotional eating significantly correlated with BMI. As BMI increased so did reported negative emotional and situational eating whereas as BMI decreased, reported positive emotional and situational eating increased. In this study, eating more under negative emotions may contribute to being overweight whereas eating under positive emotions may contribute to being underweight.

Therefore, from empirical investigations conducted so far, emotional eating has been found to be an implicating factor in body weight and BMI either by moderating the relationship between overconsumption and overweight or leading to higher BMI while external eating appears to have a less stronger influence on overeating and body weight.

In exploring emotional eating in different cultures, Luomala, Sirieix, and Tahir (2009) found that Finns react to negative emotional experiences by excessive, indulgent, and luxurious food treats and to positive emotions with solitary eating patterns. In contrast, Pakistani students associate a social and everyday eating activity to both positive and negative emotions. As for French students, they associate social and luxurious eating patterns with positive emotions, and, in the case of negative emotions, they prefer solitary eating activities. The authors suggested that the role culture plays in emotional eating activities is difficult to establish and is probably more subtle and indirect in emotional eating.

Other studies have also investigated the relationship between culture, emotional patterns and eating behaviours. Hawks et al. (2003) found that women in the US were more likely to initiate eating for emotional reasons, while women in Japan were more likely to eat for physical or environmental reasons. These results suggest that national differences in the cultural environment may impact individual motivations for eating.

The aim of the present study was to examine weight-directed behaviour and eating behaviours as they relate to BMI in a European country, Cyprus and a Middle Eastern country, Lebanon. These two countries share many similarities, including their small size, the emphasis on extended family, the central role of religion, the importance of food in family life, and the prominent portrayal of western ideals in the way of living. Lebanon and Cyprus have strong western influences since both were ex-colonies of France and Great Britain respectively. Also, both countries suffered from war which resulted in the displacement of a number of citizens. In addition, both countries are multi-cultural, enjoying a wealth of cultural and religious traditions.

However, Lebanon and Cyprus represent very different cultures mainly with respect to language and religion. In Lebanon, the religious division is $60 \%$ Muslims and $40 \%$ Christians, while in Cyprus the division is $20 \%$ and $80 \%$ respectively.

Reports of eating disturbances in the Middle East were rare in the past (Abdollahi \& Mann, 2001; Afifi-Soweid, Najem Kteily, \& Shediac-Rizkallah, 2002; Al-Adawi et al., 2002.) However, this has changed and reports of risky eating behaviors have appeared in Middle Eastern countries. Indeed, AfifiSoweid, Najem Kteily, and Shediac-Rizkallah (2002) found alarming rates of preoccupation with weight and disordered eating behaviours in Lebanese female students just beginning their college education. BMI was found to significantly influence eating and weight directed behaviours. They suggested that this population may be more at risk than that of Saudi Arabia, because of its longer westernization history; therefore, the seeming higher risk for students in Lebanon could possibly support the "westernization" hypothesis.

Also, more recently, Tamim et al. (2006) investigated risky weight control measures (vomiting or pills) among university students in Lebanon and assessed their relation to demographic, scholastic, and health risk behavioral characteristics. Among participating students, $6.1 \%$ reported practicing risky weight control measures. Analysis indicated that females constituted the majority of adolescents using risky weight control measures (74\%), as they have been acculturated into the dominant philosophy in which a strong emphasis is placed on thinness, and because of the media influence on remodeling their life styles.

Research suggests that rates of eating disturbance in European countries are consistent with rates within the United States (Tiggermann, Verri, \& Scaravaggi, 2005). Cyprus has witnessed a noticeable rise in eating disorders during the last few years. Several newspaper articles have noted the increase as well as the absence of specialized treatment in the country. Nevertheless, research on eating disorders among young Cypriot females has been limited.

Katsounari (2009) conducted a cross-cultural study investigating self-esteem, depression in relation to eating disordered attitudes in Cyprus and Great Britain. Results revealed higher rates of eating disordered attitudes and depressive tendencies in Cypriot women. According to Katsounari, there are many rea- 
sons which could explain these findings including cultural, climate-linked, economic factors and changes in body shape values.

Both Lebanese and Cypriot societies are exposed to rapid social changes including, changing roles for women (e.g., Silverstein \& Perlick, 1995) and Western media, with its portrayals of thin female bodies (e.g. Becker, 2004; Levine \& Smolak, 1998). Through the modernization process, these societies have lost some of the social norms that have traditionally protected women from weight concerns. As excessive weight concerns appear to be a proximal risk factor for maladaptive dieting behaviours and the development of eating disorders, it is important to uncover the factors that contribute to the development of these attitudes in young girls and adult women.

The current cross-cultural study was designed to examine pre-occupation with weight and eating behaviours (emotional, external, restrained eating) and their relationship to BMI in two distinct cultural contexts. Given the general eating disorder vulnerability in the Cypriot culture and the mediational factors which promote the risk for body dissatisfaction among Cypriot women (Katsounari, 2009), it was hypothesized that Cypriot women are more likely to engage in weight-directed behaviors as well as emotional, external and restraint eating compared to Lebanese women.

\section{Methods}

\section{Participants}

The study included 398 female undergraduate students aged 17 - 25 from the humanities and health sciences. The Lebanese volunteers $(\mathrm{N}=198)$ were recruited from two campuses of the Lebanese American University, one in the center of Beirut and one in the North (Byblos), and had a mean age of 19.6 years $(\mathrm{SD}=1.48)$. The Cypriot participants $(\mathrm{N}=200)$ were recruited from Frederick University in Nicosia and had a mean age of 20.03 years $(\mathrm{SD}=1.86)$. These ages reflect the typical age at which students attend university in these two countries.

Lebanese and Cypriot participants completed the questionnaires after class. The two groups represented universally distinct cultures since all the Lebanese and Cypriot participants were born and raised in Lebanon and Cyprus respectively.

Before engaging in the main study, a pilot study with ten participants having similar characteristics to the participants used in the main study was conducted in Cyprus. The pilot study was carried out in order to assess the comprehensibility of the translated items and their cultural relevance. Therefore, a few items were changed after feedback from participants indicated confusion about the meaning of these items in the particular context. Additionally, a pilot study was also conducted with a Lebanese sample in order to make sure that participants properly understood the vocabulary used.

The present study was approved by the Ethics Committee of Frederick University and the Committee on Human Subjects in Research (CHSR) of the Lebanese American University. Students were informed of the goal of the study, that participation was voluntary and that information would be kept confidential.

\section{Measures}

Measures included the BMI and the Dutch Eating Behavior Questionnaire (DEBQ) for Assessment of Restrained, Emotional, and External Eating Behavior (van Strien, Frijters,
Bergers \& Defares, 1986a).

Weight directed behavior was determined by four statements indicating whether participants were trying to lose weight, gain weight, maintain their weight or not trying to do anything about their weight.

Body Mass Index (BMI; weight in kg/height in metres ${ }^{2}$ ) was calculated using self-reported height and weight.

The Dutch Eating Behaviour Scale (DEBQ; van Strien, Frijters, Bergers, \& Defares, 1986) was developed originally in Dutch as a measure of several aspects of eating behavior. It consists of restrained, emotional, and external eating subscales. The response options range from (1) never to (5) very often, and scores are averaged across subscales with higher scores indicating high levels of restrained, emotional, or external eating. Factor analyses showed that all items on restrained and external eating have high loadings on one factor. For emotional eating behavior, two dimensions were studied: one dealing with eating in response to diffuse emotions (e.g. eating when feeling lonely, idle or bored) and the other with eating in response to clearly labeled emotions (e.g., eating in response to anger or irritation) (van Strien, Frijters, Bergers, \& Defares, 1986). The DEBQ was reported to select for exclusively restricting dieters (van Strien, 1986). Ogden (1993) evaluated the concept of restraint as measured by the restrained eating scale of the DEBQ. The study found that the term restraint is best conceptualized in terms of both attempts at dieting and successful dieting. In the current study, the DEBQ showed good internal reliability for restrained eating $(\alpha=.93)$, external eating $(\alpha=.82)$, and emotional eating $(\alpha=.95)$.

Instruments that have been previously validated in both populations would have been preferable, but was not available at the time of the study. A formal back translation was used to ensure the accuracy of the Greek translation used in the Cyprus sample. Because Lebanese American University largely operates in English, most participants were comfortable completing the materials in English. As participants' actual weight measurements could not be taken, their reported measurements were used for analyses.

\section{Statistical Analysis}

Data obtained were statistically analysed with the SPSS program for Windows, version 18.0 (SPSS, Inc., 2009). Descriptive data are presented as means \pm SEM. Analyses of frequencies were performed and contrasted for the two populations in the study. The Pearson's Correlation Statistical Test was carried out in order to establish whether there was a relationship between each of the three eating behaviours (external eating, emotional eating and restrained eating), BMI and eating behaviour in each group. Independent samples t-tests were carried out to confirm whether the difference between the means of the two samples was statistically significant. Tests applied were twotailed and statistical significance was defined as $p<.05$.

\section{Results}

\section{Demographics}

The Lebanese and Cypriot female university students ranged in their studies from first to fifth year. The largest portion of the Lebanese sample were second year students $(33.5 \%)$ while the largest portion of the Cypriot sample were first year students $(37.5 \%)$. The mean weight of the Lebanese participants was 
$57.8 \pm .6 \mathrm{~kg}$ while it was $59.1 \pm .8 \mathrm{~kg}$ for the Cypriots. The mean for BMI in the two samples was $21 \pm .2$ and $22 \pm .29$ $\mathrm{kg} / \mathrm{m}^{2}$ respectively. It should be noted that both samples fell toward the lower end of the range $(20$ - 25) considered normal (Garrow \& Webster, 1985). With respect to weight-directed behaviour, a higher percentage of Cypriot students was trying to lose weight (56.0\%versus $45.5 \%$ for the Lebanese sample), trying to gain weight ( $4.5 \%$ and $3.2 \%$ respectively), and trying to maintain weight ( $26 \%$ and $17.6 \%$ respectively). On the contrary, a higher number of Lebanese students were not trying to modify their weight (33.7\% versus $13.5 \%$ respectively).

\section{Eating Behaviors}

Regarding the eating behaviour patterns in the two cultures (Table 1), the emotional eating scores $(t(394)=3.98, p<.001$, $r=.2)$ and the external eating scores $(t(392)=3.46, p=.001, r$ $=.17)$ were lower in the Cypriot sample compared to the Lebanese sample. There was no significant difference in the restraint eating scores of the two cultures. A positive correlation between restrained eating and emotional eating was found in Cyprus and in Lebanon $(\mathrm{r}=.19, p=.007$ and $\mathrm{r}=.22, p=.002$ respectively) as well as between emotional eating and external eating $(\mathrm{r}=.31, p<.001$ and $\mathrm{r}=.32, p<.001$ respectively). External eating was found to be negatively correlated with restraint eating only within the Cypriot sample $(\mathrm{r}=-.2, p=.006)$. In both cultures, BMI was found to be correlated with the restraint eating score $(p<.001$ for both cultures) and the emotional eating score $(p=.005$ for Cyprus and $p=.01$ for Lebanon). No correlation was found between BMI and external eating scores.

\section{Discussion}

With respect to culture and weight-directed behavior, Cypriot students are more pre-occupied with their weight either by trying to gain, lose or maintain their weight. This finding confirms the hypothesis that Cypriot students would be more concerned with efforts to control their weight and confirms previous research which indicated Cypriot students' dissatisfaction concerning their weight which often leads to eating pathology (Katsounari, 2009). The presence of high concern with weight in a population is a function of its sharing some sociocultural elements that are determinant in this kind of behaviour (Bojorquez \& Unikel, 2004). Cyprus has a longer westernization history than Lebanon. Therefore, this pre-occupation can be largely attributed to unique sociocultural factors and particularly to the impact of Western influences on the way young Cypriots perceive the ideal female figure. Other significant sociocultural influences include the media, the comparison of Cypriots' figures with those of migrant women (e.g. Eastern European), and the contrast between a fast-paced, modernized way of living and the conservatism of the Cypriot society, which leads to the stigmatization of obesity (Katsounari, 2009). Ruggiero (2001a) suggests that Italy, like other Mediterranean countries, has imported Western cultural standards and modern social habits while at the same time attempting to retain its traditional values. Thus, the psychological demands resulting from cultural change influences young women's concern about their weight and subsequently their attitudes towards food and eating.

In terms of cultural differences in eating behaviors, our re-
Table 1.

Scores on eating behaviours in Lebanon and Cyprus. Data is expressed at mean \pm SEM. ${ }^{*} p<0.05$.

\begin{tabular}{ccc}
\hline Eating Behaviors & Lebanon & Cyprus \\
\hline Restrained Eating Score & $29.20 \pm .71$ & $28.14 \pm .67$ \\
Emotional Eating Score & $37.76 \pm .98^{*}$ & $32.27 \pm .97$ \\
External Eating Score & $33.33 \pm .51^{*}$ & $30.83 \pm .51$ \\
\hline
\end{tabular}

sults indicated that Lebanese female students are more likely to respond to either diffuse or clearly labeled emotional states (such as anger, anxiety, fear) by excessive eating (Bruch, 1961, 1964; Kaplan \& Kaplan, 1957) or as a response to external food-related stimuli regardless of the internal state of hunger or satiety. This finding is in disagreement with the second hypothesis of the study. It appears that although less Lebanese female students engage in behaviors which aim to control or direct their weight, they are more vulnerable than Cypriot students to engage in eating behaviors which were shown to be predictive of problematic eating (van Strien, Frijters, Bergers, $\&$ Defares, 1986). These findings indicate that eating behaviors are an issue in both cultures, however their aetiology seems to be different. Specifically, Cypriot female students have a higher intention of modifying their body weight while Lebanese female students are more inclined to regularly engage in emotional and external eating.

In both samples, there was a significant positive relationship between BMI, restraint and emotional eating. These findings are in agreement with expectations from related literature and confirm Nolan, Halperin, \& Geliebter's (2010) findings. Specifically, both emotional and restraint eating have been linked with various forms of overeating such as binge eating and bulimic tendencies. These forms of overeating are not only contributing factors for obesity but also have connections with anorexia and bulimia nervosa. These findings are also in accord with literature suggesting that an individual's final level of body weight may be determined more by people's tendency toward emotional eating than by people's sensitivity to environmental food cues (van Strien, Herman, \& Verheijden, 2009).

In addition, a significant positive relationship was found between emotional and external eating in both cultures, a finding which is in agreement with theory which views these types of eating as related. Therefore, according to our findings and related research, individuals who respond to environmental cues by eating are more likely to respond to emotions by overeating as well.

Also, in both samples, there was a significant positive relationship between restraint and emotional eating. Previous studies found moderate to low associations between these two patterns of eating (van Strien, Frijters, Bergers, \& Defares, 1986; van Strien, 1996; van Strien, Frijters, Roosen, Knuiman-Hijl, \& Defares, 1985; Waller \& Osman, 1998). Our findings agree with Herman and Polivy's viewpoint that emotional eating is more closely related to dieting (often related to overeating) than to overeating per se (e.g. Herman, Polivy, Pliner, Threlkeld, \& Munic, 1978) and that emotional eating may characterize only some dieter subtypes (Lindeman \& Stark, 2001). This is in agreement with the theory of Restraint eating which views emotional eating as a consequence of intense dieting. 


\section{Conclusion}

Female students in both cultures show a high concern for their weight, however, Cypriot students indicate a higher concern with efforts to control their weight. In contrast, Lebanese students engage in emotional and eating behaviors more often, behaviors which have been linked with eating disorder psychopathology. Findings indicate that external and emotional eating styles are related, therefore, students in these two cultures may show vulnerability towards both eating styles. In addition, intense dieting efforts may lead to relapses and particularly, increase the likelihood to eat in response to emotional cues. Furthermore, level of body weight in these two cultures is related to emotional and restraint eating styles.

To conclude, this study suggests that a general vulnerability towards eating disorder psychopathology exists in both cultural groups, but the pathways which reinforce this vulnerability differ. In Cypriot students, a higher pre-occupation with weight, which is mediated by sociocultural agents specific to this culture, is the contributing factor to eating disorder psychopathology. In Lebanese students, a higher tendency towards emotional and external eating may create a higher vulnerability towards dysfunctional eating.

Results of this study must be interpreted with caution and taking into consideration the differences between the two populations under study. First, many women in these cultures are reluctant to admit to eating behaviours which may be viewed by others as dysfunctional because of the stigma associated with eating pathology. Second, a student sample may reflect traits that are characteristic of a student population, but cannot be generalized to the general population. In addition, participants are drawn from different departments (health sciences and humanities), therefore differences in their responses may be due to the fact that health science students have knowledge of implication of body weight on the health. Last, the utilization of self reported height and weight may cause subjectivity of data which in return may affect the relationship between BMI, restraint and emotional eating.

In conclusion, this cross-cultural study explores eating behavior and patterns of preoccupation with weight in Lebanese and Cypriot students. Results indicate that eating behavior patterns present an important issue in these two cultures and can help us to better understand the rise of eating pathology in these two cultures. The findings of this study present a base for further investigation in larger studies where the etiology of the dominant eating behaviors in each culture is explored taking into account other cultural variables such as religion and the degree of westernization.

\section{REFERENCES}

Abdollahi, P. \& Mann, T. (2001). Eating disorder symptoms and body image concerns in Iran: Comparisons between Iranian women in Iran and in America. International Journal of Eating Disorders, 30, 259268. doi:10.1002/eat.1083

Affifi-Soweid, R. A., Najem Kteily, M. B., \& Shediac-Rizkallah, M. C. (2002). Preoccupation with weight and disordered eating behaviors of entering students at a university in Lebanon. International Journal of Eating Disorders, 32, 52-57. doi:10.1002/eat.10037

Al-Adawi, S., Dorvlo A. S., Al-Ismaily S. S., \& Al-Ghafry D. A. (2002). Perception of and attitude towards mental illness in Oman. Journal of Social Psychiatry, 48, 305-317. doi: $10.1177 / 002076402128783334$
Anderson-Fye, A. O. (2004). A "Coca-Cola" shape: Cultural change, body image, and eating disorders in San Andres, Belize. Culture, Medicine and Psychiatry, 28, 561-595. doi:10.1007/s11013-004-1068-4

Becker, A. E. (2004). Television, disordered eating, and young women in Fiji: Negotiating body image and identify during rapid social chance. Culture, Medicine, and Psychiatry, 28, 533-559. doi:10.1007/s11013-004-1067-5

Bojorquez, I. \& Unikel, C. (2004). Presence of Disordered eating among Mexican teenage women from a semi-urban area: Its relation to the cultural hypothesis. European Eating Disorders Review, 12, 197-202. doi:10.1002/erv.571

Bruch, H. (1961). Transformation of oral impulses in eating disorders: A conceptual approach. Psychiatric Quarterly, 35, 458-481. doi:10.1007/BF01573614

Burton, P. Smit, H., \& Lightowler, H. (2007). The influence of restrained and external eating patterns on overeating. Appetite, 49, 191197. doi:10.1016/j.appet.2007.01.007

Butler, E. A., Lee, T. L., \& Gross, J. J. (2007). Emotion regulation and culture: Are the social consequences of emotion suppression culturespecific. Emotion, 7, 1-48.

Eldredge, K., \& Agras, S. (1996). Weight and shape overconcern and emotional eating in binge eating disorder. International Journal of Eating Disorders, 19, 73-82. doi:10.1002/(SICI)1098-108X(199601)19:1<73::AID-EAT9>3.0.CO ;2-T

Garrow, J. S., \& Webster, J. (1985). Quelelet's Index $\left(\mathrm{W} / \mathrm{H}^{2}\right)$ as a measure of fatness. International Journal of Obesity, 9, 147-153.

Geliebter, A., \& Aversa, A. (2003). Emotional eating in overweight, normal weight, and underweight individuals. Eating Behaviors, 3, 341-347. doi:10.1016/S1471-0153(02)00100-9

Hawks, S., Madanat, H., Merrill, R., Goudy, M., \& Miyagawa, T. (2003). A cross cultural analysis of 'motivation for eating as a potential factor in the emergence of global obesity: Japan and the United States. Health Promotion International, 18, 153-162. doi:10.1093/heapro/18.2.153

Heatherton, T. F., Herman, C. P., Polivy, J. A., King, G. A., \& McGree, S. T. (1988). The (Mis) measurement of restraint: An analysis of conceptual and issues. Journal of Abnormal Psychology, 97, 19-28. doi:10.1037/0021-843X.97.1.19

Herman, C. P., Polivy, J., Pliner, P., Threlkeld, J., \& Munic, D. (1978). Distractibilty in dieters and nondieters: An alternative view of "externality". Journal of Personality and Social Psychology, 36, 536548. doi: $10.1037 / 0022-3514.36 .5 .536$

Kaplan, H. L. \& Kaplan, H. S. (1957). The psychosomatic concept of obesity. Journal of Nervous and Mental Diseases, 125, 181-201.

Katsounari, I. (2009). Self-esteem, depression, and eating disordered attitudes: A cross-cultural comparison between Cypriot and British young women. European Eating Disorders Review, 17, 455-461. doi:10.1002/erv. 946

Larsen, J. K., van Strien, T., Eisinga, R., \& Engels, R. C. (2007). Gender differences in the association between alexithymia and emotional eating in obese individuals. Journal of Psychosomatic Research, 60, 237-243. doi:10.1016/j.jpsychores.2005.07.006

Lindeman, M., \& Stark, K. (2001). Loss of pleasure, ideological food choice reasons and eating pathology. Appetite, 35, 263-268. doi:10.1006/appe. 2000.0357

Levine, M. P., \& Smolak, L. (1998). Media as a context for the development of disordered eating. In L. Smolak, M. P. Levine, \& R. Striegel-Moore (Eds.), The developmental psychopathology of eating disorders (pp. 235-257). Hillsdale, NJ: Erlbaum.

Luomala, H., Sirieix, L., \& Tahir, R. (2009). Exploring emotionaleating patterns in different cultures: Toward a conceptual framework model. Journal of International Consumer Marketing, 21, 231-245. doi: $10.1080 / 08961530802202818$

Macht, M., Roth, S., \& Ellgring, H. (2002). Chocolate eating in healthy men during experimentally induced sadness and joy. Appetite, 39, 147-158. doi:10.1006/appe.2002.0499

Macht, M. \& Simons, G. (2000). Emotions and eating in everyday life. Appetite, 35, 65-71. doi:10.1006/appe.2000.0325 


\section{KATSOUNARI, N. ZEENI}

Nolan, L., Halperin, L., \& Geliebter, A. (2010). Emotional Appetite Questionnaire. Construct validity and relationship with BMI. Appetite, 54, 314-319. doi:10.1016/j.appet.2009.12.004

Nasser, M. (1986). Comparative study of the prevalence of abnormal eating attitudes among Arab female students of both London and Cairo Universities. Psychological Medicine, 16, 621-625. doi: $10.1017 / \mathrm{S} 0033291700010370$

Ogden, J. (1993). The measurement of restraint: Confounding success and failure? International Journal of Eating Disorders, 13, 69-76. doi:10.1002/1098-108X(199301)13:1<69::AID-EAT2260130109>3. $\underline{0 . \mathrm{CO} ; 2-\mathrm{Z}}$

Patel, K. A., \& Schlundt, D. G. (2001). Impact of moods and social context on eating behavior. Appetite, 36, 111-118. doi:10.1006/appe.2000.0385

Polivy, J. (1976). Perception of calories and regulation of intake in restrained and unrestrained subjects. Addictive Behaviors, 1, 237243. doi:10.1016/0306-4603(76)90016-2

Polivy, J. \& Herman, C. P. (1976). Clinical depression and weight change: A complex relation. Journal of Abnormal Psychology, 85, 338. doi: $10.1037 / 0021-843 X .85 .3 .338$

Polivy, J., \& Herman, C. P. (2002). Causes of eating disorders. Annual Review of Psychology, 53, 187-213. doi:10.1146/annurev.psych.53.100901.135103

Polivy, J., Herman, C. P., \& McFarlane, T. (1994). Effects of anxiety on eating: Does palatability moderate distress-induced overeating in dieters? Journal of Abnormal Psychology, 103, 505-510. doi:10.1037/0021-843X.103.3.505

Pothos, E., Tapper, K., \& Calitri, R. (2009). Cognitive and behavioral correlates of BMI among male and female undergraduate students. Appetite, 52, 797-800. doi:10.1016/j.appet.2009.03.002

Robbins, T. W., \& Fray, P. J. (1980). Stress and dieting: Fact, fiction. Appetite, 1, 103-133. doi:10.1016/S0195-6663(80)80015-8

Rodin, J. (1978). Causes and consequences of consumption in overweight and normal weight people. Journal of Personality and Social Psychology, 12, 332-344.

Ruggiero, G. M. (2001a). One country, two cultures. In M. Nasser, M. A. Katzman, \& R. A. Gordon (Eds.), Eating disorders and cultures in transition (pp. 127-136). New York: Brunner-Routledge.

Silverstein, B., \& Perlik, D. (1995). The cost of competence: Why inequality causes depression, eating disorders, and illness in women. New York: Oxford University Press.
Schachter, S., Goldman, R., \& Gordon, A. (1968). Effects of fear, food deprivation and obesity on eating. Journal of Personality and Social Psychology, 10, 91-97. doi:10.1037/h0026284

Tamim, H., Tamim, R., Almawi, W., Rahi, A., Shamseddeen, W., Ghazi, A., Taha, A., \& Musharrafieh, U. (2006). Risky weight control among university students. International Journal of Eating Disorders, 39, 80-83. doi:10.1002/eat.20205

Tiggerman, M., Verri, A., \& Scaravaggi, S. (2005). Body dissatisfaction, disordered eating, fashion magazines, and clothes: A crosscultural comparison between Australian and Italian young women, International Journal of Psychology, 40, 293-302. doi:10.1080/00207590444000311

van Strien, T. (1996). On the relationship between dieting and "obese" and bulimic eating patterns. International Journal of Eating Disorders, $19,83-92$. doi:10.1002/(SICI)1098-108X(199601)19:1<83::AID-EAT10>3.0.C $\underline{\mathrm{O} ; 2-\mathrm{R}}$

van Strien, T., Herman, P., \& Verheijden, M. (2009). Eating style, overeating, and overweight in a representative Dutch sample. Does external eating play a role? Appetite, 52, 380-387. doi:10.1016/j.appet.2008.11.010

van Strien, T., Frijters, J. E., Bergers, G. P., \& Defares, P. B. (1986). The Dutch eating behavior questionnaire for assessment of restrained, emotional and external eating behaviour. International Journal of Eating Disorders, 5, 295-315.

doi:10.1002/1098-108X(198602)5:2<295::AID-EAT2260050209>3. $\underline{0 . \mathrm{CO} ; 2-\mathrm{T}}$

van Strien, T., Frijters, J. E. R., Roosen, R. G. F., Knuiman-Hijl, W. J., \& Defares, P. B. (1985). Eating behavior, personality traits and body mass in women. Addictive Behaviors, 10, 333-343. doi:10.1016/0306-4603(85)90029-2

Waller, G., \& Osman, S. (1998). Emotional eating and eating psychopathology among non-eating-disordered women. International Journal of Eating Disorders, 23, 419-424. doi:10.1002/(SICI)1098-108X(199805)23:4<419::AID-EAT9>3.0.C $\mathrm{O} ; 2-\mathrm{L}$

Lin, W., Hang, C.-M., Yang, H.-C., \& Hung, M.-H. (2011). 2005-2008 Nutrition and health survey in Taiwan: The nutrition knowledge, attitude and behavior of 19-64 years old adults. Asia Pacific Journal of Clinical Nutrition, 20, 309-318. 